\title{
SELECTION OF THE BEST LOCATIONS OF NEW PHOTOVOLTAIC FARMS IN JORDAN USING GIS
}

\author{
Prof. Mohammed Taleb Obaidat ${ }^{1}$; and Nour Abu Shuaib ${ }^{2}$ \\ ${ }^{1}$ Corresponding Author: Professor of Civil Engineering, President of Jadara University; E-mail: \\ mobaidat@jadara.edu.jo; In leave from: Jordan University of Science and Technology (JUST),CE \\ Dept.; College of Engineering; Jordan.E-mail: mobaidat@just.edu.jo \\ ${ }^{2}$ Mechanical Engineering Department, The University of Jordan, Amman 11942, Jordan, E- \\ mail: moonnight_1992@yahoo.com
}

\begin{abstract}
The aim of this study were to determine of best areas to construct new photovoltaic farms in Jordan using four main factors that majorly affect the feasibility of these farms which is solar radiation yearly sum on the land, aspect of the land, height of the land and the presence of electricity lines near the land. Further, to represent main current projects in Geographic Information Systems (GIS) software. The outcome results will produce a map of Jordan Suitability areas to construct new Photovoltaic farms by using GIS software and many calculations with remote sensing techniques and represent some of the current main photovoltaic projects on it as a spatial data with their names and their capacities. The new methodology will open the door for numerous GIS applications in the area of Solar Energy.
\end{abstract}

Keywords: GIS, renewable energy, solar radiation, aspect, height, electric transmission lines, and suitability. 


\section{Introduction:}

Jordan has significant sources of renewable energy, particularly solar energy. Jordan is within the belt of the solar belt, where the intensity of bright solar radiation $(5-7) \mathrm{kWh} / \mathrm{m}^{2}$, which is promising for the use of renewable energy to generate electricity in Jordan Accordingly, the overall strategy of the energy sector in Jordan, which aims to diversify sources of energy and reduce reliance on imports, has contributed to $20 \%$ of the electricity generated in 2025. In general, renewable energy is defined as the energy generated from natural and sustainable resources. The world faces major energy-related challenges as it enters the twenty-first century. Our economic wellbeing from improving urban air quality to abating the risk of global warming requires a mix of energy sources that emits less carbon dioxide and other pollutants than today's mix does [1,2, and 3].

The main consumer of electricity in Jordan is the domestic sector; the domestic electricity consumption amounted to (7448) GWh which accounts for $45 \%$ of the total consumption. The demand for electric power increased in 2016, with a growth rate of about $3 \%$. And the domestic sector recorded the highest growth rate reaching $7 \%$. Overall consumption has been steadily increasing in the recent years; due to middle-east crisis in the neighboring countries increasing the immigration from them affected Jordan's economy.

Continues to be impacted by such surrounding repercussions increasing the financial burden on our national economy resulting in low-standard- living of the citizens. Therefore, the utilization of renewable energy resources in residential sector has become a significant prominent issue. The renewable energy market has been particularly interested in solar energy in Jordan due to the rise in solar radiation .Solar radiation is the amount of solar radiation falling on a given area and capable of generating electrical power. Solar radiation is very significant in determining the site select ,as it effects energy production in the panel [3 and 5].

The solar energy is becoming one of the world's fastest growing renewable energy applications, The World Energy Council (WEC) estimated the total amount of power generated by PV panels as being 227 gigawatts, which was only $1 \%$ of world power production by the end of 2016 . And because solar energy like other sciences we seek to develop it had to be linked with the (GIS) to show the sites that were installed solar cells in which also discuss the factors that affect the solar energy and choose the most suitable location to open new projects of solar energy [4, 5 and 6$]$.

\section{Relation of site and factors:}

2.1 Solar radiation is the major criteria Because it's the primary source of energy and even the cells types are vary on its efficiency of solar power conversion to electricity the solar radiation captured from sun by this land in specific period is the base of this energy .

2.2 presence of Electric lines near to the land of project is essentially because the majority of this 
project are grid connected project which need to be connected with the national grid to work efficiently without electricity storage issues or network lines extending costs or event. The losses when the project is very far from the network because produced electricity is distributed through local electricity transmission network. Thus, this network should be considered in PV site selection.

2.3 Aspect (the compass direction that a land slope faces) is another factor which is very important to select the land to construct photovoltaic farms because its playing an important role with the energy yield amount that the piece of land get from the sun in the day.

\subsection{Height of the land}

As height of land from the mean sea level decrease the particle and pollution in the atmosphere increase so the amount of solar radiation absorbed and reflected in atmosphere increase which means that energy yielded from sun decreases for this piece of land .

\section{Data Collection \& Layer Preparation:}

\subsection{Global Tilted Irradiation:}

Sum of direct and diffuse solar radiation falling on a tilted surface of fixed-mounted PV modules $\left[\mathrm{kWh} / \mathrm{m}^{2}\right]$ as shown in Figure 1. Compared to the horizontal surface, the tilted surface also receives a small amount of ground-reflected solar radiation and this map covering the period 1999-2015 when get it from the global solar atlas website which is funded their project funded by world bank https://globalsolaratlas.info then we optimized this data and exclude the abnormal values from the raster map and classify its data from low to high using suitable color ramp to show the difference efficiently [1 to 6$]$.

\subsection{Electricity Transmission Network lines:}

This were the most difficult part of data to collect because lack of well-formed information as a spatial data firstly we took a small fragment transmission lines from National Electric Power company then, we used the existence published maps to redraw the detailed lines in the GIS software as a spatial data which shown on Figure 2.

\subsection{Current main P.V farms that have a a capacity larger than 1 M.W:}

Although lack of information available resources we collect these data from many of them like Energy \& Minerals Regulatory Commission of Jordan and solar companies websites then we take these raw data and extract the accurate position of the farms from Jordan department of lands and survey GIS online software that's located at: http://maps.dls.gov.jo in an acceptable formula (x.y decimal wgs84 coordinates) to represent it in the GIS software and sometimes we had to convert the data we got from Amman explorer online GIS software from EPSG:7142 Palestine 1923 / Palestine Grid modified system to EPSG: 4326 WGS 84 system so we can represent it in our GIS project correctly . 


\subsection{Height and Aspect:}

From Digital Elevation Model (DEM) of Jordan from satellite maps and then we derived aspect data from the GIS software then the two layers resampled and transformed to $0-100$ scale using linear function for elevation data and trigonometric

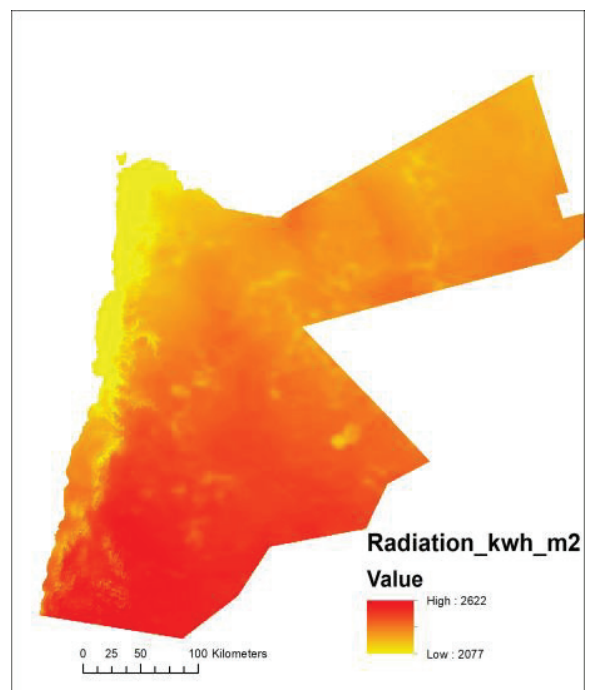

Figure 1: Solar radiation of well tilted surface

Figure 3: Study Area. function (Cosine) for aspect data to be the best aspect is the south facing and the most bad aspect is the north facing. Figure 3 shows the studied location, while Figure 4 shows height, aspect, and current main photovoltaic projects in Jordan; and Figure 5 shows the electricity grid presented effect.

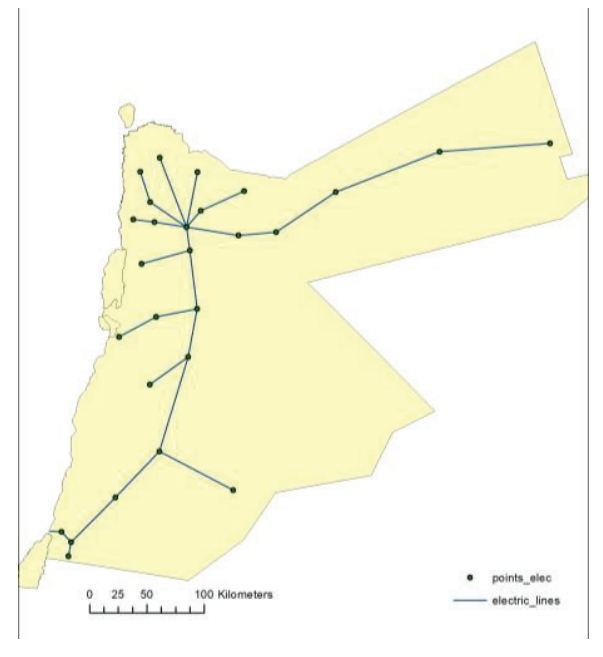

Figure 2: Electricitylines Jordan

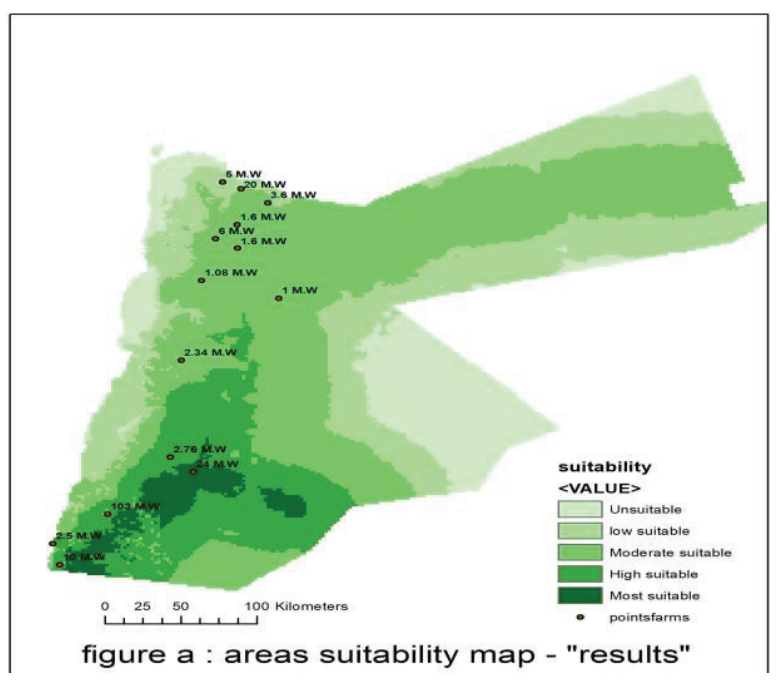




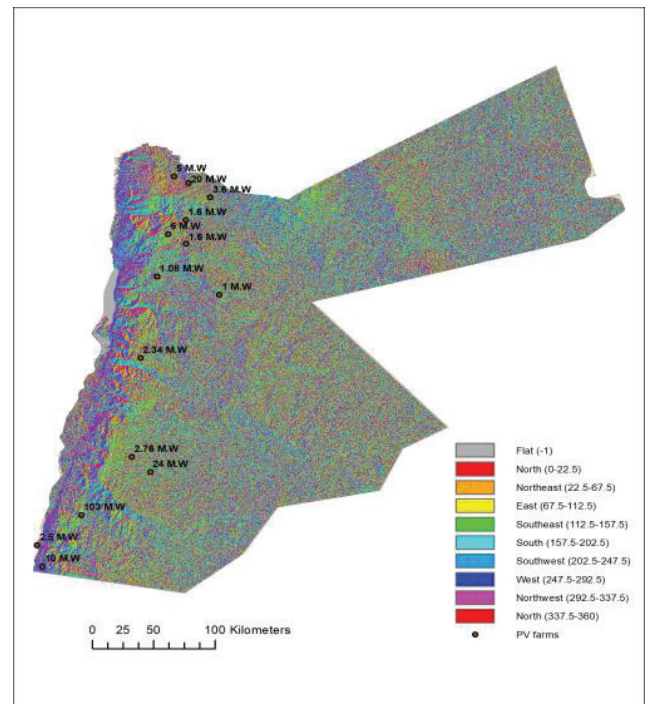

Figure 4-b: Aspect of Jordan lands.

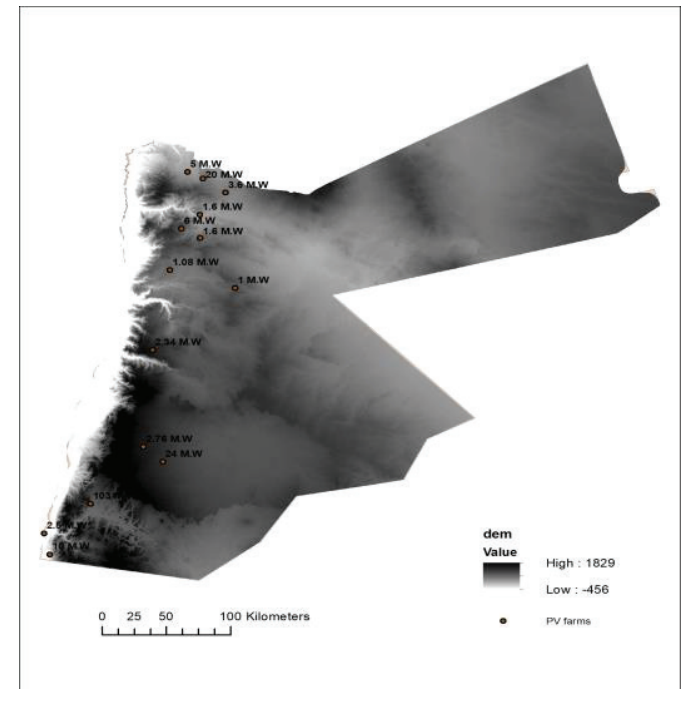

Figure 4-a: Height of Jordan Figure: Lands DEM.

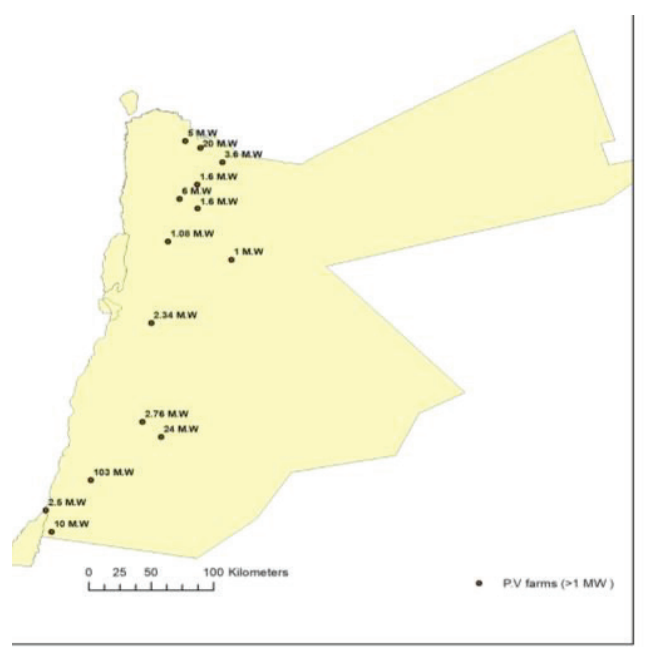

Figure 4-c: Current main photovoltaic farms in Jordan.

Figure 4: Height, aspect, and current main photovoltaic projects in Jordan. 


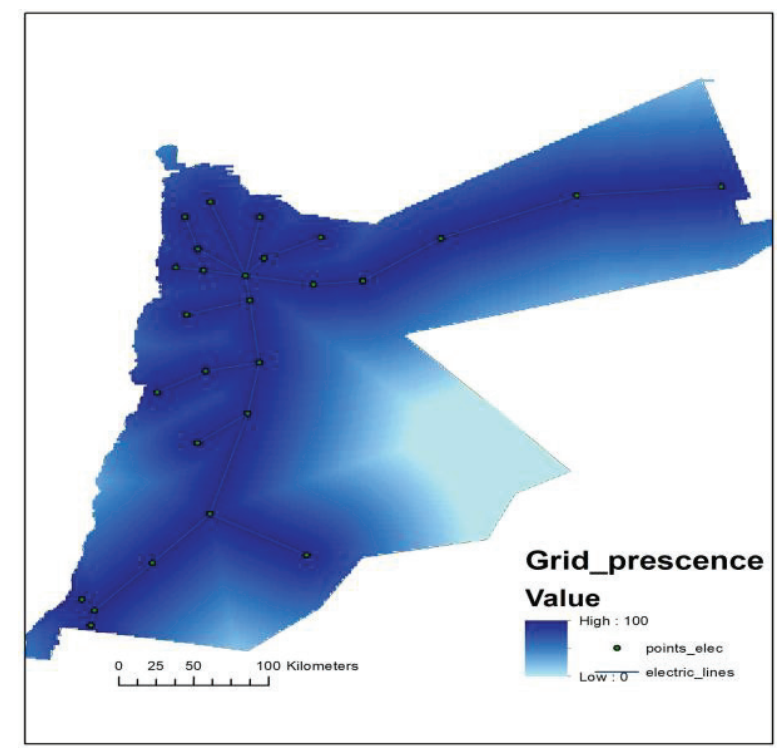

Figure 5: Electricity grid presence effect.

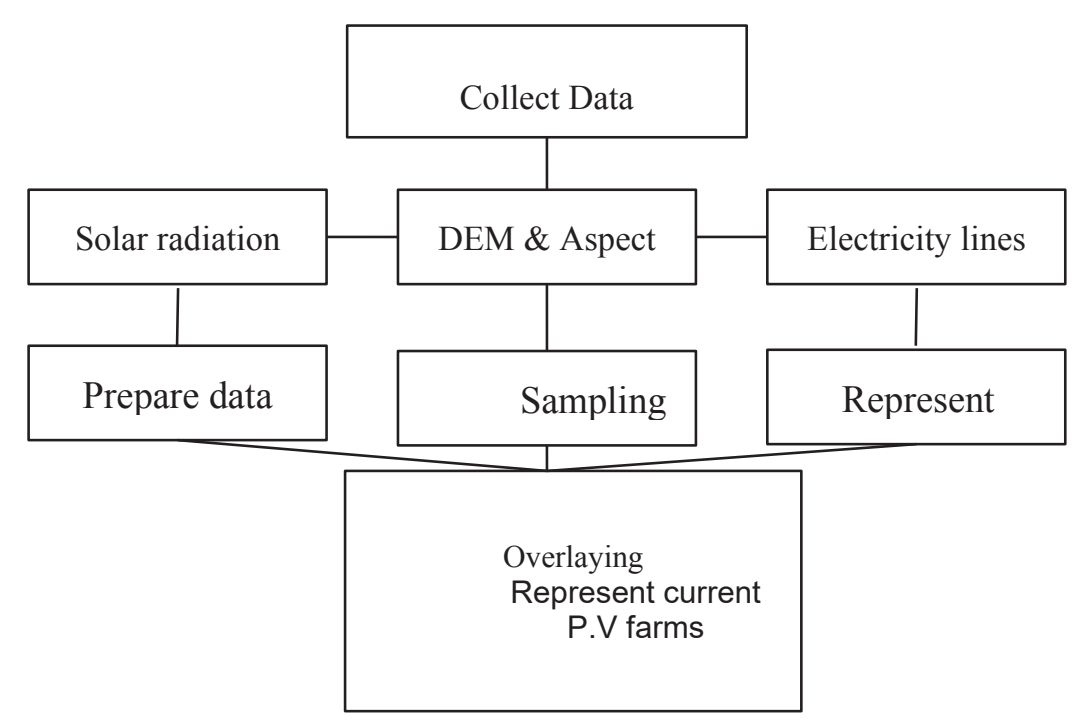

\section{Study Scope:}

In this study, the whole land area of Jordan $\left(\sim 88788 \mathrm{~km}^{2}\right)$ was selected as the study area. Jordan is a developing country located in a semi-arid hot zone in the Middle East (between $29^{\circ}$ and $32^{\circ}$ north and $35^{\circ}$ and $39^{\circ}$ east) (see Figure 3). Jordan's population amounts to 9.5 million and experienced a relatively high growth rate of $4.2 \%$ at the end of 2015 ; and for representing the current main photovoltaic farms we took farms bigger than $1 \mathrm{M} . \mathrm{W}$ in their capacities in different governorates at Jordan. 
5. Methodology \& procedure

The methodology and procedure used is presented in Figure 6. Figure 6: Methodology Procedure.

\subsection{Grid Presence Layer}

After plotting the network lines as spatial points and lines (vector type) on the map of Jordan; Euclidean Distance tool has been used on the ArcGIS software which produce raster layer and calculates. For each cell of the new raster, the Euclidean distance to the closest source (network lines in our case) and select a blue color ramp representing the values so we got the map shown in the Figure 5.

\subsection{Uniforming Rasters' Values}

We used the math tools from the software to transform those raster values and solar radiation values into 0-100 range scale using linear function for all layers except cosine function for aspect layer as it's a degree layer in order to be suitable for the next overlaying step.

\subsection{Over laying layers}

As the last operation to get our resulted map shown in results section we used overlay tool from ArcGIS for the prepared four layers with weighted sum function giving the four layers

factors as their importance increase as this:

$25 \%$ of height values $\quad>10 \%$

of the Suitability.

$50 \%$ of aspect values $\quad>20 \%$ of the

Suitability.

$75 \%$ of electricity presence values $\quad>30 \%$ of the Suitability.

$100 \%$ of the solar radiation values $\quad>40 \%$ of the Suitability.

\section{Results:}

After overlaying the two prepared layers with weighted scale as the importance of these four main factors are increasing as mentioned in 5.3; we got these maps presented at Figures 7 and 8 for suitable areas at Jordan for Photovoltaic farms.

We noticed that in Figure 7 as we go far from electric network lines the suitability decreased because of the high losses in electricity transmission and the high cost to connect the farm with the electric grid.

More detailed in Figure 8 a non-linear factor that affect such piece of land differently which is aspect affect the suitability so we saw a more accurate suitability map than previous Figure on lands level. 


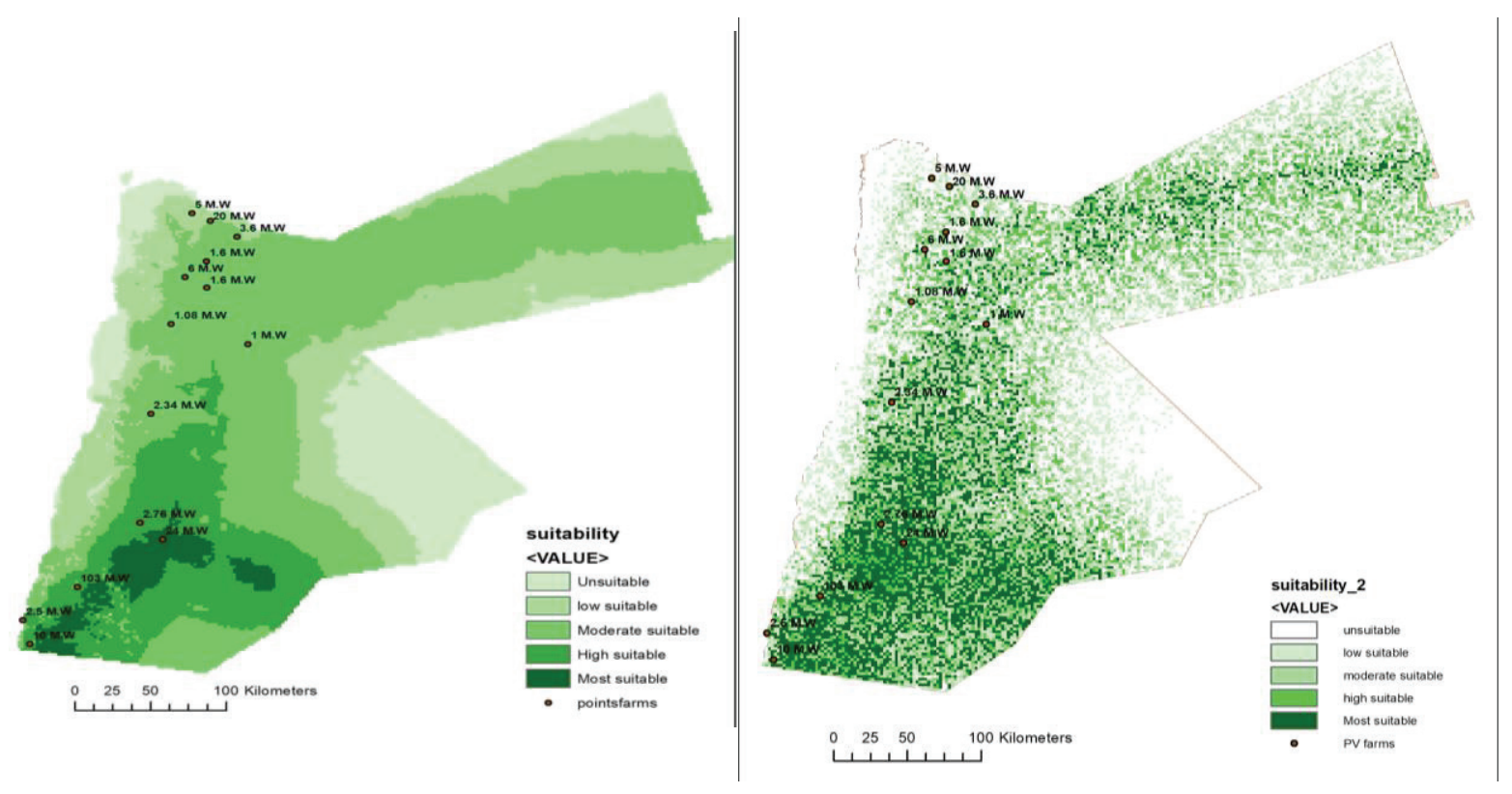

Figure 7: Photovoltaic farms areas using solar

Figure 8: Photovoltaic farms areas using all studied factors. radiation and grid presence.

\section{Conclusions:}

We realized that Jordan has huge capabilities in Photovoltaic and solar power sector and as we can see in Figures 7 and 8 current Photovoltaic farms studied in this article were located at moderate to high suitable areas but no photovoltaic farms were constructed on the non-suitable areas and the biggest farms " shams ma'an " where located in the most suitable areas of Jordan .

Furthermore, even within the electric lines presence area the suitability of areas are varying as the other important factors "solar radiation, aspect, height " are changing dynamically according to the previous criteria maps of Jordan.

\section{Recommendations:}

Despite the findings of this study, it is still recommended to:

1. Include another factors may affect the suitability such as price of the lands, land uses, etc.

2. Collect more spatial data about the current Photovoltaic farms and represent it on the map. 


\section{References:}

1. Lands and survey Department of Jordan http://www.dls.gov.jo

2. EMRC Energy and Minerals regulatory Commission and their website http://www.emrc.gov.jo

3. MEMR (Ministry of Energy and Mineral Resources), Ministry of Energy, and Mineral Resources Annual Report. 2015. http:// www.memr.gov.jo/echobusv3.0/SystemA ssets/6df2053d-ee21- 4fa0-ada8613049ab7015.pdf (accessed June 13, 2017).

4. DPS (Department of Population Statistics), Population and Social Statistics. 2015. http://web.dos.gov.jo/wpcontent/ uploads/2016/04/No_of_pop_depand_on_ GOV.pdf (accessed June 13, 2017)

5. REN21, Renewables 2017 Global Status Report.

6. NEPCO Report of 2016 http://www.nepco.com.jo 